\title{
Precarização e informalização do trabalho feminino urbano no Goiás contemporâneo
}

\author{
FRANCINE BASILE*
}

\begin{abstract}
R esumo: O presente estudb procura analisar, a partir dos dadbs da Pesquisa Nacional por Amostra de Domicílios (Pnad, IBGE), em quais condições de emprego e renda cresceu a participação feminina no mercado de trabalho do estado de Goiás. O intuito é tentar identificar, quantificar e compreender os graus envolvidos de informalização e precarização das condições, relações e ganhos do trabalho feminino na atual dinâmica do mercado de trabalho goiano. A informalidade é aqui tratada como um movimento de degradação da qualidade das ocupaçães exercidas e de precarização das formas de inserção da mão-dedora feminina no mercado de trabalho. Os critérios utilizadbs têm como base a evolução das taxas de participação da mão-de-dora na PEA, os níveis de desemprego e rendimento, a estrutura ocupacional da PFA e as modificaçães no grau de formalização das ocupaçães segundo gênero e setor da atividade econômica em Goiás ao longo dos anos compreendidos entre 1993 e 2003.
\end{abstract}

Palavras-chave: trabalho; gênero; informalidade.

\section{Introdução}

Temos assistido, nas últimas décadas, a um crescimento notável do número de trabal hadores exercendo suas atividades à margem de qualquer regulamentação, controle e proteção por parte do poder público. 0 contingente de vendedores ambulantes, autônomos, empregados sem carteira assinada e trabalhadores domésticos sem registro não pára de crescer e tem despertado a atenção dos estudiosos sobre suas condições de vida e de trabalho.

Sabemos que é evidente a importância do trabalho dito informal em termos de geração de postos de trabalho no Brasil. Segundo M attoso (1999), a Pesquisa M ensal de Emprego do Instituto B rasileiro de G eografia e Estatística (PME/IB GE, 1999), realizada nas seis maiores regiões metropolitanas do país, revel ou que, em 1999, aproximadamente quase a metade da população ocupada encontrava-se na informa-

\footnotetext{
* Professora da Universidade Estadual de Goiás - UnUCSEH - UEG.
}

lidade, grande parte sem registro e garantias mínimas de proteção e saúde, direito a aposentadoria e seguro-desemprego; ou seja, com sinais claros de degradação das condições de trabal ho e de seguridade social. A O rganização Internacional do Trabal ho (OIT) estima que seis de cada dez novos postos de trabal ho gerados desde 1990 no Brasil são informais, e essa proporção tem aumentado nos últimos anos (Tokman, 2001).

$\mathrm{Não}$ existe um consenso na área quanto à correta definição do termo trabalho informal. $\mathrm{Na}$ verdade, há uma miríade de ocupações, completamente distintas entre si em diversos aspectos, que compõem esse mercado. Mas podemos compreender a natureza dessas ocupações a partir de suas características comuns.

Os estudos de vários especial istas ${ }^{1}$ demonstram que tais ocupações caracterizam-se pela precariedade nas condições, relações e ganhos de trabalho. São exercidas em longas e instáveis jornadas de trabalho, cujos ganhos são baixos e

1. Singer (2000), M attoso (1999), Pochmann (1999, 2000), Bosco (2003) e Dalbosco (2000). 
incertos para os padrões médios de rendimento e estabilidade dos trabal hadores formais. Não têm acesso aos direitos sociais e trabal histas básicos nem a qualquer tipo de registro, controle ou proteção por parte das instituições públicas, o que as tornam continuamente sujeitas à repressão policial e à espoliação de intermediários, usuários, fiscais e policiais corruptos. A presentam baixa qualificação e reduzida produtividade.

0 fenômeno da informal idade não é recente no país, e muito menos no mundo, mas, na década de 1990, atingiu proporções alarmantes. Segundo M attoso (1999) e Bosco (2003), o $B$ rasil nunca conviveu com um grau tão crescente de deterioração e vulnerabilidade das condições e relações de trabal ho como a partir dessa década.

$N$ ão devemos nos esquecer de que, ao longo do século $X X$, o país se transformou em uma economia industrial e urbana capaz de ampliar significativamente tanto a participação dos assal ariados entre os trabalhadores ocupados como os mecanismos institucionais de proteção ao trabalhador. Porém, já a partir dos anos de 1980, o mercado de trabalho formal perde seu dinamismo e começa a surgir com relativa intensidade o problema do desemprego urbano e da deterioração das condições de trabal ho. Nos anos de 1990, a geração de empregos passa a refletir as profundas transformações estruturais da economia brasileira e o baixo desempenho de suas atividades econômicas, fazendo "explodir" os indicadores de desemprego e precariedade do trabalho, independentemente da metodologia utilizada para mensurálos.

Paralelamente ao processo de intensa informalização do mercado de trabal ho urbano no país, houve mudanças significativas na composição da força de trabalho. Um dos aspectos mais relevantes dessa modificação diz respeito à ampliação das taxas de participação das mulheres na atividade econômica.

Porém, a expansão do emprego feminino nas últimas décadas vem ocorrendo em condições de trabalho pouco favoráveis a uma inserção de qualidade no mercado de trabalho. Segundo Scorzafave (2004), Leone (2003) e outros, ${ }^{2}$ apesar de ocorrer um aumento da participação feminina nos espaços formal e informal do mercado de trabalho, ele se traduz em sua maioria nas áreas nas quais predominam os empregos mais precários, vulneráveis e de baixa remuneração e em situações de pobreza, exploração e exclusão social. Constata-se que as taxas de desemprego feminino e a proporção de mulheres ocupadas em condições de informalidade são maiores que as masculinas (Tokman, 2001). N esse sentido, a crescente participação da mulher na força de trabal ho tem sido marcada pela desigual dade de inserção, de remuneração e de oportunidades, com conseqüências diretas sobre a qualidade de vida de suas famílias.

Parece, portanto, que estamos diante de um paradoxo: o forte crescimento do emprego feminino no país, capaz de proporcionar maior autonomia e participação nas decisões da vida social, política e econômica para as mulheres, ocorreu, si multaneamente, em meio a uma crescente degradação e informalização das condições e relações de trabalho.

Quando nos deparamos com esses dados e informações, as perguntas são inevitáveis. Q uais são os fatores responsáveis pelo crescimento do trabalho informal e, notadamente, do trabal ho informal feminino nas últimas décadas do século $X X$ ? Será que a deterioração do mercado de trabal ho está restrita a al gumas regiões ou podemos generalizar a análise, geralmente concentrada nos seis maiores centros urbanos, para o restante das cidades brasileiras? Quem são as trabalhadoras informais do estado de Goiás e como se comportam os indicadores capazes de capturar a sua presença na sociedade? Podemos também afirmar que são as mulheres, sobretudo as mulheres adultas goianas, as mais atingidas pelo fenômeno da informalidade e precariedade dos novos postos de trabalho gerados, à semelhança do que vem ocorrendo em outras regiões?

As respostas fazem-se necessárias e urgentes para a elaboração e a aplicação de políticas públicas sociais adequadas ao atendimento da população, bem como à compreensão do próprio fenômeno, no contexto de desenvol-

2. Hirata (2003), Valenzuela (2003), Bruschini (1995), Roy (1999) e Cacciamali (2002). 
vimento da economia goiana, para a construção de mecanismos eficazes na superação dos padrões históricos de pobreza e desigualdade social. Como nos ensina Tokman (2001), o problema do emprego diz respeito nem tanto ao desemprego em si, mas principalmente àquelas ocupações que não permitem 0 acesso dos indivíduos às condições adequadas de trabal ho e renda, agravando os índices de pobreza e a situação de exclusão social.

Portanto, este trabal ho pretende identificar, quantificar e analisar, a partir dos indicadores de formalidade e precariedade da ocupação em Goiás, a evolução e a atual dinâmica da participação das mulheres no mercado de trabal ho goiano, de forma a compreender a dimensão do fenômeno da informalidade sobre as relações e condições de trabalho por gênero.

Os dados utilizados para este estudo foram extraídos da Pesquisa Nacional por A mostra de Domicílios (Pnad), realizada anualmente pelo Instituto Brasileiro de Pesquisa e Estatística (IBGE), referente aos anos de 1993 a 2003. Dentre os indicadores empregados, encontramse aquel es relacionados ao perfil da PEA feminina no estado, como participação na atividade econômica, desemprego, distribuição ocupacional, grau de formalização das ocupações em nível setorial e variação no nível de rendimento médio.

Definimos mercado de trabalho informal como um mercado de compra e venda de serviços de mão-de-obra sem registro institucional e desprovido de qual quer vínculo com a seguridade social pública. Esse mercado é representado pel os empregados remunerados e/ ou não, cujos contratos de trabalho não são regidos pelos regimes cel etistas ou estatuários, e pelos trabal hadores que exercem ocupações por conta própria, para outros ou para consumo e uso próprio, sem qualquer tipo de regulamentação, controle e proteção por parte das legislações vigentes - fiscais, trabal histas, previdenciárias e ambientais.

Consideraremos como trabal hador informal as seguintes categorias ocupacionais: empregado e trabalhador doméstico sem carteira assinada, trabal hador por conta própria, trabaIhador não-remunerado e trabalhador na produção ou construção para o próprio consumo e uso. É importante salientar que não desconsideramos os problemas teóricos e metodológicos pertinentes a essa classificação, mas foi necessário adotar um critério de definição para tornar a análise viável.

Iniciamos nosso estudo a partir da análise das alterações ocorridas no perfil da PEA feminina em Goiás, verificando as taxas de participação econômica e de desemprego. Em seguida, traçamos um breve panorama do desenvolvimento recente da economia goiana, deforma a contextualizar as principais mudanças ocorridas no mercado de trabalho do estado. Final mente, verificamos as princi pais mudanças na estrutura ocupacional, o grau de formal ização das ocupações, por setor econômico e gênero, e a evolução do nível de rendimento médio das mulheres ocupadas para compreender e avaliar o quadro de informalidade presente nas condições e relações de trabal ho feminino em Goiás.

\section{Características e evolução da PEA feminina em Goiás}

A o longo das últimas décadas do século $X X$, as mulheres ampliaram seu espaço no mercado de trabalho urbano brasileiro, configurando um processo que ficou conhecido como femininização do trabalho. ${ }^{3}$ Segundo Leone (2003), naúltima década do século $X X$ houve uma nítida expansão da ocupação feminina de forma generalizada em todas as principais regiões metropolitanas do país. A análise da ocupação feminina no Brasil, em qualquer das regiões mencionadas, confirma também que a população economicamente ativa (PEA) feminina ficou mais madura no período.

No estado de Goiás, esse fenômeno foi semel hante. Conforme os dados da Pesquisa

\footnotetext{
3. Vários são os fatores, amplamente discorridos pela literatura, envolvidos nesse processo. Quedas substanciais nos indicadores de fecundidade nacional; maiores dificuldades de composição da renda familiar, obrigando a busca de trabaIho remunerado por parte das esposas; maiores níveis de escolaridade alcançados pela população feminina, e o aprofundamento do processo de urbanização e industrialização da economia nacional, que permitiu tanto a ampliação dos postos tradicionais de emprego feminino como a inserção da mão-de-obra feminina em setores tradicionalmente ocupados pelo gênero masculino, bem como a criação de novos postos de trabalho nos diversos segmentos do setor de serviços (Leone, 2003 e Cacciamali, 2002).
} 
Nacional por A mostra de Domicílios (Pnad/ IBGE), a população em idade ativa (PIA) cresceu, entre 1993 e 2003, 3,17\% ao ano, passando de 3.304 .617 pessoas para 4.352 .155 em 2003. Em função do acelerado processo de urbanização, tal fenômeno esteve concentrado no crescimento da população urbana, já que a população rural apresentou taxas negativas de crescimento.

Em relação à composição da população ativa, houve um crescimento ligeiramente mais expressivo da população feminina no estado: mais 538.626 mulheres - acima de dez anos ou mais - vieram constituir a população ativa do estado entre 1993 e 2003, perante um adicional de 508.912 homens no período. A través dos dados da Tabela 1, podemos verificar que a PIA feminina cresceu $32,41 \%$ e a masculina, $30,98 \%$ no período. 0 ritmo de crescimento foi mais intenso para as faixas de maior idade, tanto para a população masculina quanto para a feminina. Isso revela a configuração de uma população mais adulta e feminina no estado.

Tabela 1 - Taxas de crescimento da PIA por gênero Goiás, anos: 1993-2003 (\%)

\begin{tabular}{|c|c|c|}
\hline $\begin{array}{c}\text { PIA FEMININA } \\
1993-2003\end{array}$ & $\begin{array}{c}\text { PIA MASCULINA } \\
1993-2003\end{array}$ & $\begin{array}{c}\text { PIA TOTAL } \\
\mathbf{1 9 9 3 - 2 0 0 3}\end{array}$ \\
\hline 32,41 & 30,98 & $\mathbf{3 1 , 7 0}$ \\
\hline
\end{tabular}

Fonte: IBGE: Pnads, 1993-2003.

Elaboração da própria autora; PIA= população em idade ativa.

Em relação ao crescimento da população economicamente ativa (PEA) em Goiás, de um contingente de 1.572 .723 pessoas em 1993 , a PEA urbana passou para 2.335 .186 pessoas em 2003 , revelando um crescimento no período de $48,48 \%$, praticamente de $5 \%$ ao ano na média.

0 crescimento da PEA urbana foi mais intenso notadamente para a popul ação feminina. Os dados das Tabelas 1 e 2 expressam que, apesar do crescimento da população ativa em taxas médias anuais de $3,5 \%$, a PEA urbana cresceu a um ritmo muito mais intenso para a população feminina - o crescimento médio girou em torno de $6,65 \%$ ao ano e foi visivelmente inferior para a população masculina, em média de $3,75 \%$ ao ano.

Em 1993, 37,47\% da PEA urbana estava constituída pelo gênero feminino e $62,53 \%$, pelo masculino. Já em 2003, a PEA urbana passou a ser constituída por $42,06 \%$ de mulheres e $57,94 \%$ de homens, o que demonstra um significativo aumento da participação das mulheres no mercado de trabal ho goiano.

Há que se considerar, porém, que o gênero masculino, apesar de representar metade da população no estado, ainda tem uma maior participação no mercado de trabal ho, dado que sua participação na PEA urbana total ainda é superior à feminina, apesar do crescimento relativo mais intenso desta última nos últimos anos do período.

Tabela 2 - Taxas de crescimento da PEA urbana por gênero. Goiás, anos: 1993-2003 (\%)

\begin{tabular}{|c|c|c|}
\hline $\begin{array}{c}\text { PEA FEMININA } \\
\text { urbana }\end{array}$ & $\begin{array}{c}\text { PEA MASCULINA } \\
\text { urbana }\end{array}$ & $\begin{array}{c}\text { PEA TOTAL } \\
\text { urbana }\end{array}$ \\
\hline 66,65 & 37,59 & $\mathbf{4 8 , 4 8}$ \\
\hline
\end{tabular}
Fonte: IBGE: Pnads, 1993-2003.
Elaboração da própria autora.
PEA = população economicamente ativa.

A o longo do período considerado, a parcela da PIA que participa do mercado de trabalho, como ocupado ou desocupado, sofreu pouca alteração: de $60,11 \%$ em 1993, a participação cresceu para $61,05 \%$. 0 que na verdade sofreu al teração diz respeito à composição, por gênero e idade, dessa participação, como podemos observar a partir dos dados da Tabela 3.

Quanto à composição etária da população economicamente ativa de Goiás, dois fatos chamaram nossa atenção: a queda de participação da PIA muito jovem e jovem - população entre 10 e 14 anos de idade e 15 e 19 anos, respectivamente, no mercado de trabalho; e 0 crescimento relativamente mais intenso da participação da PIA adulta - população acima de 25 anos.

Em relação à composição por gênero, é notável o crescimento da participação da PIA feminina adulta no mercado de trabal ho, assim como a queda, em todos os grupos etários, da participação da PIA masculina. A s responsáveis pelas maiores taxas de participação feminina foram mulheres entre 30 a 39 anos (68,90\%), e entre 25 a 29 anos $(66,29 \%)$.

Portanto, a análise dos dados da Pnad permite constatar uma ampliação significativa das taxas de participação feminina na PEA de Goiás, apesar do crescimento menos intenso da 
Tabela 3 - Taxas de participação da população no trabal ho por gênero e fai xa etária. Goiás, anos: 1993-2003 (\%)

\begin{tabular}{|l|cc|cc|cc|}
\hline \multirow{2}{*}{$\begin{array}{c}\text { FAIXAS DE } \\
\text { IDADE }\end{array}$} & \multicolumn{2}{|c|}{$\begin{array}{c}\text { TAXA FEMININA } \\
\text { urbana }\end{array}$} & \multicolumn{2}{c|}{ TAXA MASCULINA } & \multicolumn{2}{c|}{$\begin{array}{c}\text { TAX TOTAL } \\
\text { urbana }\end{array}$} \\
\cline { 2 - 7 } & 1993 & 2003 & 1993 & 2003 & $\mathbf{1 9 9 3}$ & $\mathbf{2 0 0 3}$ \\
\hline 10 a 14 anos & 15,89 & 7,63 & 27,75 & 8,50 & $\mathbf{2 1 , 8 4}$ & $\mathbf{8 , 0 9}$ \\
\hline 15 a 19 anos & 45,77 & 45,77 & 76,94 & 56,43 & $\mathbf{6 1 , 1 7}$ & $\mathbf{4 9 , 5 6}$ \\
\hline 20 a 24 anos & 55,99 & 63,40 & 92,69 & 89,78 & $\mathbf{7 3 , 9 7}$ & $\mathbf{7 6 , 1 3}$ \\
\hline 25 a 29 anos & 55,20 & 66,29 & 96,67 & 94,80 & $\mathbf{7 4 , 7 7}$ & $\mathbf{8 0 , 2 0}$ \\
\hline 30 a 39 anos & 59,68 & 68,90 & 97,17 & 95,51 & $\mathbf{7 7 , 3 0}$ & $\mathbf{8 1 , 6 1}$ \\
\hline 40 a 49 anos & 50,10 & 65,21 & 95,84 & 91,64 & $\mathbf{7 2 , 6 1}$ & $\mathbf{7 7 , 9 9}$ \\
\hline 50 a 59 anos & 38,52 & 44,51 & 79,06 & 84,29 & $\mathbf{5 8 , 5 7}$ & $\mathbf{6 3 , 2 6}$ \\
\hline 60 anos ou mais & 14,57 & 15,73 & 50,34 & 42,86 & $\mathbf{3 0 , 7 3}$ & $\mathbf{2 8 , 1 9}$ \\
\hline TOTAL & $\mathbf{4 3 , 6 7}$ & $\mathbf{5 0 , 1 6}$ & $\mathbf{7 7 , 6 4}$ & $\mathbf{7 2 , 4 7}$ & $\mathbf{6 0 , 1 1}$ & $\mathbf{6 1 , 0 5}$ \\
\hline
\end{tabular}

Fonte: Pnads, 1993-2003

Elaboração da própria autora; Taxa de participação $=($ PEA/PIA $) \times 100$

população feminina, a qual cresceu em ritmo praticamente semelhante à masculina, ainda que superior à média nacional. Os dados também revel am al terações no perfil etário das trabal hadoras goianas: houve um crescimento maior do trabalho feminino adulto na atividade econômica - mulheres acima de 25 anos, apesar do crescimento significativo em quase todas as faixas etárias, com exceção das mais jovens.

Em um quadro de maior participação da mulher no mercado de trabal ho, torna-se pertinente analisar a capacidade e a qualidade de absorção de um maior contingente de trabal hadoras na atividade econômica de Goiás, visto que a década de 1990 foi marcada pela exacerbação dos fenômenos do desemprego urbano e da informalidade nas relações e condições de trabalho no país. Ou seja, será que foram gerados postos de trabal ho formais em número suficiente pela economia goiana capazes de absorver todo o crescimento da PEA feminina no estado?

\section{Evolução das taxas de ocupação do emprego feminino em Goiás}

A análise das taxas de ocupação e desocupação do emprego em Goiás permite verificar que a ampliação das taxas de participação feminina no mercado de trabalho foi acompanhada, no entanto, de um forte aumento nas taxas de desemprego feminino.
No período compreendido entre 1993 e 2003, o número de ocupados em Goiás cresceu de 1.936.231 para 2.352.144 pessoas, o que corresponde a um crescimento de $21,48 \%$ no estoque de emprego total. Pel o corte de gênero, a ocupação masculina cresceu $16,97 \%$ no período e a feminina, a um percentual visivelmente superior - 29,42\%.

Esses percentuais de crescimento não foram suficientes para absorver 0 incremento de mão-de-obra no mercado de trabal ho. Com isso, em ambas as categorias, houve queda nas taxas de ocupação da PEA, e a redução no percentual de homens ocupados foi inferior à redução no de mulheres ocupadas - se em 1993, $95,28 \%$ da PEA masculina estava ocupada, em 2003 apenas $93,37 \%$ estava, diante de um percentual de $93,33 \%$ da PEA feminina ocupada em 1993, que sofreu redução em 2003 para $88,19 \%$, conforme expressam os dados da Tabela 4.

Isto significa que 0 forte ingresso das mulheres no mercado de trabal ho em Goiás foi acompanhado por um crescimento mais intenso das mulheres no contingente populacional desempregado, em relação aos homens.

A taxa de desemprego masculina entre 1993 e 2003 cresceu praticamente 40,50\%, elevando-se de $4,72 \%$ para $6,63 \%$, enquanto a taxa de desemprego feminina cresceu mais intensamente, $77,06 \%$, saindo de um patamar de $6,67 \%$ para se estabelecer em $11,81 \%$ ao 
Tabela 4 - Total de trabalhadores ocupados por gênero e taxa de ocupação. Goiás, anos: 1993-2003

\begin{tabular}{|c|c|c|}
\hline INDICADORES & 1993 & 2003 \\
\hline PEA masculina & 1.296 .399 & 1.547 .331 \\
\hline Homens ocupados & 1.235 .163 & 1.444 .814 \\
\hline Taxa de ocupação (\%) & 95,28 & 93,37 \\
\hline PEA feminina & 751.162 & 1.028 .815 \\
\hline Mulheres ocupadas & 701.068 & 907.330 \\
\hline Taxa de ocupação (\%) & 93,33 & 88,19 \\
\hline PEA total & 2.047 .561 & 2.576 .146 \\
\hline Total de ocupados & 1.936 .231 & 2.352 .144 \\
\hline Taxa de ocupação (\%) & 94,56 & $\mathbf{9 1 , 3 0}$ \\
\hline
\end{tabular}

final do período, como podemos observar na Tabela 5.

A taxa de desemprego, para a população total em Goiás, cresceu em torno de $60 \%$ nos últimos dez anos, passando de 5,44\% em 1993 para $8,70 \%$ em 2003 , o que revela uma taxa média de desemprego em torno de 6,9\% ao ano, inferior à taxa de desemprego feminino.

No quesito idade, 0 aumento do desemprego atingiu de forma generalizada todas as faixas etárias. Porém, ao longo do período, ele se comportou com maior intensidade entre a população feminina jovem, o que pode ser compreendido como uma maior dificuldade de inserção das jovens mulheres no mercado de trabalho em Goiás.

L eone (2003) e Q uadros (2003) observam que as maiores dificuldades enfrentadas pelos jovens na busca de trabal ho revelam um fenômeno de melhor adequação da mão-de-obra adulta às alterações ocupacionais recentes: em razão tanto de sua maior experiência, qualificação e escolaridade e, de certa forma, pelo fato de que as ocupações que mais cresceram nos anos 90, como empregadores e trabal hadores por conta própria, tradicionalmente serem ocupações da população adulta.

Nesse sentido, 0 aumento da participação feminina na ati vidade econômica em G oiás não foi acompanhado por um crescimento suficiente de oportunidades ocupacionais de trabalho, como indicam as crescentes taxas de desemprego desse gênero ao longo do período analisado. $\mathrm{Na}$ verdade, entre as mulheres jovens ocorreu um decréscimo acentuado nas taxas de ocupação, revelando as significativas dificuldades do mercado de trabalho em absorver novas parcel as dessa população. Por outro lado, a efetiva partici pação das mulheres na atividade econômica vem ocorrendo de forma a absorver com maior intensidade aqueles grupos de mulheres mais adultas, refletindo uma mudança importante no comportamento feminino - a sua permanência, mesmo casada e com filhos, no trabal ho.

A trel ado a esse fenômeno de maior desemprego entre as mulheres no estado, deve-se verificar em que condições o trabal ho feminino passou a ser incorporado ao processo produtivo, e isso no que diz respeito ao perfil ocupacional, à qual idade dos empregos gerados eàs relações de trabal ho estabelecidas.

Tabela 5 - Evolução das taxas de desemprego por gênero. Goiás, anos: 1993; 1997; 1999; 2001 e 2003

\begin{tabular}{|c|c|c|c|c|c|}
\hline INDICADORES & 1993 & 1997 & 1999 & 2001 & 2003 \\
\hline Mulheres ocupadas & 701.068 & 781.910 & 781.800 & 909.890 & 907.330 \\
\hline Mulheres desempregadas & 50.094 & 73.090 & 111.876 & 107.957 & 121.485 \\
\hline Taxa de desemprego $(\%)$ & 6,67 & 8,55 & 12,52 & 10,61 & 11,81 \\
\hline Homens ocupados & 1.235 .163 & 1.398 .670 & 1.408 .703 & 1.504 .571 & 1.547 .331 \\
\hline Homens desempregados & 61.236 & 83.358 & 103.602 & 102.159 & 102.517 \\
\hline Taxa de desemprego $(\%)$ & 4,72 & 5,96 & 7,35 & 6,79 & 6,63 \\
\hline Total ocupados & 1.936 .231 & 2.097 .222 & 2.086 .901 & 2.312 .302 & 2.352 .144 \\
\hline Total desempregados & 111.330 & 156.448 & 215.478 & 210.116 & 224.002 \\
\hline Taxa de desemprego $(\%)$ & 5,44 & 6,94 & 9,36 & 8,33 & 8,7 \\
\hline
\end{tabular}


3. A nálise das condições de ocupação da mão-de-obra feminina em Goiás no contexto econômico da década de 1990 e início do século XXI

A profunda transformação na estrutura produtiva da economia nacional ao longo dos anos de 1990, com lento crescimento do Produto Interno Bruto (PIB) e pouco investimento, provocou fortes impactos no nível e nas condições de emprego no país, o que deve ser compreendido através das mudanças que por ela foram geradas na dinâmica do mercado de trabal ho nacional. Os resul tados mais imediatos dessas mudanças foram: a) redução dos postos de trabalho formais; b) terceirização de atividades, com queda de participação do setor industrial na geração de empregos e crescimento de ocupações no setor terciário - neste último, foram criadas novas oportunidades de trabal ho de natureza precária, se considerarmos fatores como estabilidade, segurança e remuneração. As medidas econômicas implementadas nos anos de 1990, que ficaram conhecidas genericamente pelo termo políticas neoliberais, e que moldaram o processo de reestruturação produtiva da economia, promoveram alguns efeitos perversos sobre a dinâmica setorial de geração de empregos formais no país. Tais medidas levaram à modernização da economia, com muita importação, à desintegração das cadeias produtivas, à racionalização das atividades na empresa, dado o aumento de sua exposição à competição dos produtos importados, e a baixas taxas de investimento e crescimento do produto que, al iadas às novas tendências de organização do trabal ho nas grandes empresas, visando basicamente à redução de custos de produção, acabaram por provocar impacto devastador sobre o mercado de trabal ho assalariado, com a eliminação significativa de postos de trabal ho preexistentes, sem a criação de novos. ${ }^{4}$

É importante ressaltar, segundo Leone (2003), que a queda no grau de formalização da mão-de-obra na economia nacional não está

4. Essas e outras considerações sobre o processo de reestruturação produtiva da economia brasileira nos anos 90 e seus impactos sobre o mercado de trabalho podem ser verificadas em M attoso (1999), Pochmann (1999), B altar (2003) e Roy (1999). relacionada apenas à redução do ritmo de atividade dos setores que proporcionavam oportunidades de ocupação formal e à expansão do ritmo de atividade dos que criavam ocupações ditas informais; houve também um processo de reestruturação da atividade dos primeiros que culminou na geração de postos de trabal ho não formalizados.

No que diz respeito à economia goiana, os novos rumos da economia nacional tiveram repercussão semelhante sobre o mercado de trabal ho do estado. No entanto, é necessário considerar que os movimentos de reestruturação e desregulamentação econômica, com crescimento do emprego informal e precário, tiveram impactos peculiares sobre a economia e o mercado de trabalho de Goiás. Isso ocorreu em função das características particulares do seu processo de desenvolvimento econômico e da forma como o estado tem se integrado nas últimas décadas do século $X X$ à economia nacional.

Para M aia (2005), Silva (2002) e Estevam (1998), o processo de urbanização e industrialização de Goiás, como elemento promotor de transformações socioeconômicas na sociedade e de progresso técnico nas atividades produtivas, que desemboca no fenômeno clássico de assalariamento e formalização da mão-de-obra, "decol ou" no estado só a partir dos anos de 1970. A o longo do século XX, Goiás conquistou o seu espaço na economia nacional como fornecedor de alimentos e matérias-primas e como entreposto comercial, ligando as Regiões Norte e Sul do país. A atividade industrial predominante esteve voltada à oferta de bens alimentares semi processados e, apenas no final do século, 0 setor industrial, que era frágil e sem relevância econômica, diversificou-se, com uma maior oferta de produtos tanto tradicionais quanto novos - porém, ainda concentrado na produção de bens de consumo.

É por esse motivo que esses autores chamam a atenção para o caráter tardio, rápido, intenso e desordenado do processo de urbanização e modernização econômica do estado a partir da construção de Brasília. Enquanto a indústria se consolidava como importante gerador de renda e emprego no Sudeste, aumentando sobremaneira sua participação no PIB, em Goiás el a ainda não se apresentava, relativamen- 
te aos demais setores, como uma área de destaque na economia regional. 0 que apenas recentemente foi alterado, mas de forma ainda modesta.

Nos anos de 1990, houve uma nítida desaceleração das taxas de crescimento econômico do estado, o que já era observado desde os anos de 1980, apesar da variação do PIB goiano não ter sido tão brusca quanto a nacional. Esse fato deve-se à alta participação do setor agropecuário na composição do PIB do estado, o qual absorveu impactos menos negativos, no que diz respeito à produção, do que 0 industrial, com 0 processo de abertura e desregulamentação do mercado nacional. Esse comportamento também foi observado nos últimos anos, inclusive com relativa mel hora nos indicadores do PIB e da participação da economia goiana na nacional, como expressam os dados da Tabela 6 .

A pesar do ritmo de crescimento recente da economia goiana se apresentar em patamar superior ao nacional, tal crescimento não foi suficiente para gerar novas oportunidades de trabal ho compatíveis com o ritmo de crescimento da PEA urbana no estado, em particular da feminina. A o longo dos últimos dez anos (19932003), a economia goiana cresceu a um ritmo médio anual de $3,9 \%$, enquanto a população no período cresceu a um ritmo médio anual de 3,2\% e a PEA urbana, a um ritmo mais intenso - em torno de $5 \%$ ao ano; a PEA feminina evoluiu na média de $6,5 \%$ ao ano.

A análise setorial revela que 0 setor agropecuário foi o que obteve melhor desempenho econômico no estado ao longo dos anos de 1990, seguido pelo setor de serviços e o industrial este último enfrentou taxas de crescimento negativas em 1990, 1991, 1995 e 1998. Enquanto o setor agropecuário cresceu 59,7\%, o setor de serviços evoluiu $33,1 \%$ e 0 industrial, $21,8 \%$ neste período (Silva, 2002).

Nos últimos anos, o setor agropecuário continua revelando um bom desempenho econômico - entre 2001 e 2002, a produção agropecuária cresceu $7,82 \%$, adquirindo maior participação no PIB do estado. 0 crescimento do setor industrial foi relativamente modesto, se comparado ao do agropecuário: entre os anos de 2001 e 2002, a produção industrial cresceu $3,26 \%$ e sua participação no PIB estadual caiu de $35,03 \%$ para $32,62 \%$, retornando praticamente ao mesmo patamar verificado em 2000. Já o PIB do setor de serviços apresentou um crescimento maior que o industrial - em torno de $4,53 \%$, porém vem apresentando ano a ano queda de participação no PIB do estado; em 2001, sua participação era de $47,44 \%$ do PIB, caindo para 44,87\% em 2002 (Tabela 7). Como resultado, atualmente a participação de cada um dos setores no PIB goiano é mais equilibrada do que no início dos anos de 1990.

A pesar do sucesso econômico obtido pelo setor agropecuário nos últimos anos, ele foi 0 responsável por uma grande perda de empregos no meio rural, intensificando o processo de urbanização precária e caótica nos centros urbanos e exacerbando as taxas de desemprego. Como o setor industrial teve um crescimento apenas moderado, inclusive negativo em 1995 e 1998, e historicamente nunca foi capaz de gerar um

Tabela 6 - PIB , taxas de crescimento e participação no PIB nacional. G oiás, anos: 1993, 1997, 1999, 2001 e2002*

\begin{tabular}{|c|c|c|c|c|c|}
\hline \multirow[b]{2}{*}{ ANO } & \multicolumn{2}{|c|}{$\begin{array}{l}\text { PRODUTO INTERNO BRUTO } \\
\text { em valores correntes / R\$ milhão** }\end{array}$} & \multicolumn{2}{|c|}{$\begin{array}{c}\text { TAXAS DE CRESCIMENTO } \\
(\%)\end{array}$} & \multirow{2}{*}{$\begin{array}{c}\text { PARTICIPAÇÃO NO } \\
\text { PIB NACIONAL } \\
(\%) \\
\text { GOIÁS }\end{array}$} \\
\hline & GOIÁS & BRASIL & GOIÁS & BRASIL & \\
\hline 1993 & 707.503 & 14.039 .352 & 6,4 & 4,9 & 1,83 \\
\hline 1997 & 16.025 & 870.743 & 5,2 & 3,3 & 1,84 \\
\hline 1999 & 17.920 & 973.846 & 3,1 & 0,8 & 1,84 \\
\hline 2001 & 25.048 & 1.198 .736 & 4,3 & 1,3 & 2,09 \\
\hline 2002 & 31.299 & 1.346 .028 & 4,9 & 1,9 & 2,33 \\
\hline
\end{tabular}

Fonte: Seplan-GO/ Sepin - Gerência de Contas Regionais /IBGE - Departamento de Contas Nacionais.

Elaborado pela própria autora.

* O PIB de Goiás consolidado para o ano 2003 não foi apresentado até o fechamento desta pesquisa

** Em R\$ milhão para o ano de 2003. 
número razoável de novas ocupações, coube novamente ao setor de serviços absorver o crescimento da população economicamente ativa do estado, o que ocorreu conforme as características de ocupação da mão-de-obra nesse setor, ou seja, com a geração tanto de postos de trabalho formais quanto informais e precários.

A s análises do Dieese-GO (2003), de Silva (2002) e M aia (2005) confirmam que, ao longo dos anos de 1990, e mesmo nos últimos anos, 0 setor que tem gerado o maior número de postos de trabalho no estado é o de serviços, com destaque para o comércio. Os dados levantados por Silva (2002) demonstram que, em 1992, esse setor foi o responsável pela geração de 50,6\% de postos de trabalho em Goiás e atingiu em 1999 um percentual de $64,6 \%$ de ocupação da mão-de-obra formal. Já a indústria tem apresentado menor dinamismo na geração de novos postos de trabalho, e a agricultura vem eliminando postos de trabalho ano após ano no estado.
Segundo os dados do Censo 2000 do IB GE, relatados em estudo do IBGE (2003) sobre 0 mercado de trabalho goiano e expressos aqui na Tabela 8, há um predomínio de trabalhadores assalariados entre a população ocupada tanto no $B$ rasil quanto no estado. Porém, no B rasil, 0 percentual de trabalhadores assalariados com carteira de trabalho assinada em relação aos que não têm um vínculo formal é superior $36,98 \%$ dos ocupados são assalariados com cartei ra diante de $24,31 \%$ sem carteira, o que já não ocorre em G oiás. Os dados revelam que os percentuais de participação dessas categorias - assal ariado com carteira e sem carteira - são muito próximos, $31,71 \%$ e $31,65 \%$ respectivamente. Ou seja, há no estado uma maior proporção percentual de trabalhadores sem carteira de trabal ho do que o verificado no país.

Se considerarmos os trabalhadores por conta própria, 22,07\% da população ocupada, mais os trabalhadores sem remuneração e os trabalhadores para o próprio consumo, que repre-

Tabela 7 - Taxa real de variação do PIB total e por setor (\%). Goiás, anos: 1995, 1997, 1999, 2001 e2002

\begin{tabular}{|c|c|c|c|c|}
\hline Ano & PIB Total & PIB Agropecuária & PIB Industrial & PIB Serviços \\
\hline 1995 & 1,84 & 4,20 & $-0,84$ & 2,43 \\
\hline 1997 & 5,27 & 8,61 & 7,29 & 3,41 \\
\hline 1999 & 3,17 & 4,53 & 3,18 & 2,76 \\
\hline 2001 & 4,30 & 7,37 & 2,39 & 4,52 \\
\hline 2002 & 4,90 & 7,82 & 3,26 & 4,53 \\
\hline
\end{tabular}

Fonte: Seplan-GO / Sepin / Gerência de Estatística Socieconômica - 2003

Tabela 8 - Ocupados por posição na ocupação e categoria de emprego. B rasil e Goiás: 2000

\begin{tabular}{|c|c|c|c|c|}
\hline \multirow{2}{*}{ CARACTERÍSTICAS } & \multicolumn{2}{|c|}{ BRASIL } & \multicolumn{2}{|c|}{ GOIÁS } \\
\hline & $(\%)$ da PEA & (\%) dos ocupados & $(\%)$ da PEA & (\%) dos ocupados \\
\hline PEA & 100,00 & -- & 100,00 & -- \\
\hline Com carteira assinada & 31,42 & 36,98 & 27,83 & 31,71 \\
\hline Militares e func. públicos & 4,90 & 5,76 & 6,35 & 7,23 \\
\hline Sem carteira assinada & 20,65 & 24,31 & 27,78 & 31,65 \\
\hline Empregadores & 2,42 & 2,84 & 3,48 & 3,96 \\
\hline Conta própria* & 19,00 & 22,36 & 19,37 & 22,07 \\
\hline Trabalhador sem remuneração & 3,35 & 3,95 & 1,23 & 1,40 \\
\hline Tralhador p/ consumo e uso próprio & 2,48 & 2,92 & 1,01 & 1,15 \\
\hline Ocupados & 84,96 & 100,00 & 87,77 & 100,00 \\
\hline
\end{tabular}

Fonte: IBGE, Censo 2000 (tabulação avançada - subamostra).

Elaboração: Dieese/GO; reelaboração: da própria autora.

* Definimos o trabalhador por conta própria como aquele indivíduo que trabalha explorando o seu próprio empreendimento, sozinho ou com sócio, sem ter empregado e contando, ou não, com a ajuda de trabalhador não-remunerado, conforme metodologia empregada pelo IBGE. 
sentam $1,40 \%$ e $1,15 \%$, respectivamente, dos ocupados, chegamos à conclusão de que mais da metade da população ocupada no estado, $56,27 \%$, exerce suas atividades de maneira informal e precária no que diz respeito ao baixo grau de estabilidade, segurança e remuneração no trabalho.

E mbora o mercado de trabal ho formal em Goiás tenha expandido o número de postos de trabalho em um ritmo significativamente superior à média nacional na década de 1990 - o percentual de crescimento foi de $52,71 \%$ para 0 estado e apenas $13,06 \%$ para o país, provocando inclusive um crescimento de sua participação em relação ao total de empregos formais no país -, o grau de informalidade e precariedade no mercado de trabalho goiano ainda é relativamente superior ao nacional, como indicam os dados apresentados.

A lém do mais, o mercado de trabal ho formal em Goiás ainda é predominantemente ocupado pelo sexo masculino - em 2000,60,82\% das vagas formais de trabal ho foram destinadas à população masculina, enquanto $39,18 \%$ à feminina. Portanto, se tal disparidade existe, um corte analítico de gênero se torna imprescindível para compreender a situação das mulheres trabal hadoras no mercado de trabal ho goiano.
4. A nálise da distribuição e da formalização da ocupação feminina no estado de Goiás

0 avanço da participação das mulheres na força de trabal ho econômica nas últimas décadas do sécul $\mathrm{XX}$, sobretudo das mulheres adultas, tanto no país como no estado, esteve concentrado no dinamismo do setor terciário, que tradicional mente apresenta el evado grau de informalização e precarização das relações e condições de trabalho (L eone, 2003 e Dieese-G 0, 2003).

A análise dos indicadores de distribuição da ocupação feminina da Pnad (1993 a 2003) permite afirmar que foram as atividades do setor terciário aquelas que mais empregaram a mãode-obra feminina no estado. Se, em 1993, 70\% das trabal hadoras atuavam no setor de serviços, em 2001 este percentual subiu para 83\%, como indicam os dados da Tabela 9.

O correram, entre 1993 e 2001, uma notável perda de partici pação do setor agrícola na geração de postos de trabal ho feminino - e é importante ressaltar que foi o setor econômico de melhor desempenho no estado - e um ganho apenas moderado de participação do setor industrial, confirmando o perfil terciário da ocupação feminina em Goiás.

Tabela 9 - Distribuição da ocupação feminina por setor e grupo de atividade. Goiás, anos: 1993-2001 (\%)

\begin{tabular}{|c|c|c|c|c|}
\hline \multirow[b]{2}{*}{ Setores e grupos de atividades } & \multicolumn{2}{|c|}{$\begin{array}{c}\text { Dis tribuição das mulheres adultas } \\
\text { ocupadas - } 1993\end{array}$} & \multicolumn{2}{|c|}{$\begin{array}{c}\text { Distribuição das mulheres adultas } \\
\text { ocupadas }-2001\end{array}$} \\
\hline & Total & $\%$ ocupadas & Total & $\%$ ocupadas \\
\hline Agrícola & 168.009 & 22,85 & 84.820 & 8,79 \\
\hline Indústria & 53.041 & 7,21 & 76.148 & 7,89 \\
\hline Ind. de transformação* & 49.439 & 6,72 & 72.933 & 7,55 \\
\hline Construção civil & 3602 & 0,49 & 3.215 & 0,34 \\
\hline Serviços & 514066 & 69,92 & 803.859 & 83,31 \\
\hline Comércio de mercadorias & 77281 & 10,51 & 146.504 & 15,18 \\
\hline Prestação de serviços & 88074 & 11,98 & 150.026 & 15,54 \\
\hline Serviços domésticos & 175173 & 23,82 & 240.650 & 24,94 \\
\hline Transporte e comunicação & 3274 & 0,44 & 9.635 & 0,99 \\
\hline Atividades sociais & 110016 & 14,96 & 168.362 & 17,44 \\
\hline Administração pública & 29468 & 4,00 & 53.986 & 5,59 \\
\hline Serviços auxiliares ativ.ec. & 18992 & 2,58 & 24.418 & 2,53 \\
\hline Outras & 11788 & 1,6 & 10.278 & 1,06 \\
\hline Total & 735116 & 100,00 & 964.827 & 100,00 \\
\hline
\end{tabular}

Fonte: IBGE: Pnad 1993, 1999 e 2001. Elaboração da própria autora

* e outras atividades industriais. 
Em 2001, as atividades que mais empregaram a mão-de-obra feminina foram, em ordem decrescente, os serviços domésticos $(25 \%)$, as atividades sociais (educação, saúde, previdência e assistência social: 17,5\%), de prestação de serviços (pessoais, domésticos e domiciliares: $15,5 \%$ ) e comércio (15\%).

A o final do período, esse perfil ocupacional sofreu poucas al terações. $\mathrm{Na}$ Tabela 10 , observa-se que, em 2003, a maior parte das mulheres ocupadas ainda permanece fortemente concentrada no setor de serviços, a uma taxa ainda superior à de 1993 (78\%). Entretanto, o setor industrial ganhou mai or participação, com notável crescimento de postos de trabal ho ao longo do período, apesar de não se revelar um empregador significativo da mão-de-obra feminina em relação aos demais (13\%). Chama a atenção o crescimento da participação das atividades da administração pública, quase $60 \%$ no período, ocupando $6 \%$ da PEA feminina no estado.

No ramo de prestação de serviços, os serviços domésticos ainda contam com a maior parcela de ocupadas no estado, 22,5\%. Podemos afirmar que o serviço doméstico tem um papel importante na absorção de mulheres no mercado de trabalho, provavelmente das pouco escolarizadas e das mais maduras que nele permanecem, na falta de outras oportunidades ocupacionais. $\mathrm{N}$ ão podemos nos esquecer que a ocupação doméstica, em todas as sociedades, sempre representou a porta de entrada das migrantes rurais no mercado de trabal ho urbano, como anal isa L eone (2003). E, como o setor agrícola no estado tem expulsado intensamente a mãode-obra do campo, principalmente a mão-deobra feminina, a ocupação doméstica torna-se um espelho das dificuldades de inserção no mercado urbano dessas migrantes.

Por outro lado, graças à disponibilidade de mulheres para um trabal ho de baixa qualificação e remuneração, e à falta de serviços coletivos de atendimento à família, como creches, as demais tiveram a possibilidade de consolidar sua participação no mercado de trabalho, inclusive em setores não tradicionais de absorção da mão-de-obra feminina.

Contudo, a significativa participação do trabal ho doméstico na ocupação feminina vem ocorrendo com elevado grau de precariedade,

Tabela 10 - Distribuição e variação da ocupação feminina por setor e grupo de atividade. Goiás, anos: 2003 e $1993-2003(\%)$

\begin{tabular}{|l|r|r|r|}
\hline \multirow{2}{*}{ Setores e grupos de atividades } & \multicolumn{2}{|c|}{$\begin{array}{c}\text { Distribuição das mulheres adultas } \\
\text { ocupadas - 2003 }\end{array}$} & $\begin{array}{c}\text { Variação da dis tribuição } \\
\mathbf{1 9 9 3 - 2 0 0 3}\end{array}$ \\
\cline { 2 - 4 } Agrícola & \multicolumn{1}{|c|}{ Total } & \% ocupadas & $\mathbf{( 6 1 , 8 8 )}$ \\
Indús tria & $\mathbf{8 5 . 5 3 2}$ & $\mathbf{8 , 7 1}$ & $\mathbf{7 8 , 3 6}$ \\
Indústria de transformação* & $\mathbf{1 2 6 . 1 4 5}$ & $\mathbf{1 2 , 8 6}$ & 87,35 \\
Construção civil & 123.483 & 12,59 & $(46,93)$ \\
Serviços & 2.662 & 0,26 & $\mathbf{1 1 , 7 5}$ \\
Comércio e reparação & $\mathbf{7 6 6 . 5 4 9}$ & $\mathbf{7 8 , 1 4}$ & $* *$ \\
Alojamento e alimentação & 165.747 & 16,89 & $* *$ \\
Transporte, armazenagem e comunicação & 40.615 & 4,14 & $* *$ \\
Administração pública & 13.980 & 1,42 & 57,75 \\
Educação, saúde e serviços sociais & 61.909 & 6,31 & 9,09 \\
Serviços domésticos & 160.115 & 16,32 & $-4,86$ \\
Outros serviços coletivos, sociais e pess. & 222.344 & 22,66 & $* *$ \\
Outras atividades & 60.563 & 6,17 & $* *$ \\
Atividades mal defin. ou não declaradas & 41.276 & 4,2 & s/d \\
\hline Total & - & s/d & - \\
\hline
\end{tabular}

Fonte: IBGE: Pnad 1993,2001 e 2003. Elaboração da própria autora.

* E outras atividades industriais. ** Em função de alterações metodológicas na classificação e grupamento de atividades pelo IBGE a partir de 2002, não é possível, a priori, estabelecer uma base comum de comparação a partir da construção de uma série histórica, que envolva os anos de 1993 até 2003, no que diz respeito às atividades pertencentes ao setor de serviços. 
tendo em vista as condições de baixa remuneração e formalização desse tipo de ocupação mais de $90 \%$ das trabalhadoras domésticas não têm registro em carteira e ganham menos de dois salários mínimos por mês.

A gora, em segundo e terceiro lugares, na distribuição da ocupação feminina, encontramos, respectivamente, as atividades de comércio $(17 \%)$ e as sociais ( $16,5 \%)$, conforme a nova classificação de grupos de atividades que o IB GE passou a adotar a partir de 2002. Portanto, a expansão do emprego feminino nos últimos anos concentrou-se, sobretudo, nas ocupações de prestação de serviços e comércio, setores que, como já afirmado, tradicionalmente apresentam baixo grau de formalização do trabalho. As atividades sociais continuam importantes como tradicionais geradoras de postos de trabalho feminino, porém, acabaram perdendo posição ao longo do período.

$\mathrm{Não}$ podemos afirmar que esse perfil de ocupação é próprio das características de absorção do mercado de trabal ho goiano porque, se adotarmos um corte analítico por gênero, podemos observar, pelos dados da Pnad - 1993 e 2003, que a distribuição da população masculina é mais equilibrada: se, em 1993, 70\% do emprego feminino se destinava ao setor de serviços, quanto ao masculino, esse percentual era de apenas $42 \%$, sendo que o setor industrial absorvia $21 \%$ dos homens e 0 agrícola, 36,5\%. Em 2003, enquanto a participação feminina no setor de serviços subiu para $78 \%$, a masculina também cresceu, só que a um percentual de $52 \%$, enquanto 0 setor industrial absorveu $25 \%$ e 0 agrícola, 23\% (Tabela 11).
Por outro lado, pode-se afirmar que as atividades da construção civil, por suas exigências de baixa qual ificação e escolaridade, bem como pouca remuneração, equiparam-se às ocupações femininas nas atividades domésticas remuneradas e, por isso mesmo, os migrantes homens se encaixam nas mesmas situações descritas com relação às mulheres migrantes. Se isto pode ser verdade para o país, o mesmo não pode ser dito para Goiás - quanto ao percentual de participação dos homens nessa atividade, em 1993, a construção civil ocupava $11 \%$ dos homens; em 2001, 13\% e, em 2003, 12\%, lembrando que, conforme visto anteriormente, as taxas de desemprego masculino foram menores que as femininas no período.

A ssim, pelo menos com base no que esses dados revelam, a situação dos homens é menos precária do que a das mulheres, no que diz respeito à distribuição ocupacional .

Essefato torna-se mais nítido vislumbrandose os dados da Tabela 12. Se avaliarmos o perfil ocupacional dos trabalhadores goianos conforme sua posição no trabalho principal, um recorte analítico por gênero revela que as mul heres têm ocupado, ao longo do período, um percentual maior de postos de trabalho precários e/ou informais: em 1993, 71\% das trabalhadoras se encontravam ou em empregos sem carteira de trabaIho assinada, ou por conta própria, trabal hadoras sem remuneração ou em atividades para o próprio consumo ou uso. Esse percentual foi de $66 \%$ para os homens em 1993. Embora em 2003 esses indicadores demonstrem uma mel hora na qualidade dos trabalhos ocupados, em função do aumento do grau de assal ariamento da força

Tabela 11 - Distribuição e variação ocupacional por gênero e por setor e grupo de atividade. Goiás, anos: 2003 e $1993-2003(\%)$

\begin{tabular}{|c|c|c|c|c|c|c|}
\hline \multirow[t]{3}{*}{$\begin{array}{l}\text { Grupo de } \\
\text { atividade }\end{array}$} & \multicolumn{6}{|c|}{$\begin{array}{l}\text { Distribuição das pessoas de } 10 \text { anos ou mais de idade, } \\
\text { ocupadas na semana de referência }\end{array}$} \\
\hline & \multicolumn{4}{|c|}{2003} & \multicolumn{2}{|c|}{$\begin{array}{c}\text { Variação da distribuição } \\
1993-2003\end{array}$} \\
\hline & Total Mulher & \% ocupados & Total Homem & $\%$ ocupados & Mulher & Homem \\
\hline Agrícola & 85.532 & 128,71 & 341.75 & 22,90 & $(61,88)$ & 37,38 \\
\hline Indústria & 126.145 & 12,86 & 374.103 & 25,08 & 78,36 & 19,42 \\
\hline Serviços & 766.549 & 78,14 & 774.504 & 51,94 & 11,75 & 22,44 \\
\hline Total & 980.888 & 100,00 & 1.491 .081 & 100,00 & -- & -- \\
\hline
\end{tabular}

Fonte: IBGE: Pnad 1993 e 2003. Elaboração da própria autora. 
de trabal ho e do número de empregos com carteira assinada para ambos os sexos, a diferença persiste com um percentual de $58 \%$ para os homens e $59 \%$ para as mulheres, agora, porém, em patamares mais próximos.

0 aumento do emprego com carteira para as mulheres ocorreu, porém, paralelamente a um aumento do emprego sem carteira assinada - se, em 1993, 11,5\% das mulheres ocupadas estavam empregadas sem registro em carteira e 16\%, com registro em carteira, em 2003 esses percentuais subiram para $14 \%$ e $23 \%$, respectivamente. Para a população masculina, o emprego com carteira subiu, enquanto o sem carteira diminuiu (IBGE, Pnad 1993-2003).

Portanto, o crescimento da participação feminina no mercado de trabalho goiano vem expressando, ao longo dos anos, a dificuldade de geração de postos de trabalho feminino formais e menos precários, dado o fato de que quase $60 \%$ das mulheres adultas ocupadas em 2003 estarem presentes em atividades terciárias precárias, com baixo grau de formalização e rendimento.

Os dados revelam que foram as atividades de prestação de serviços pessoais e sociais e 0 comércio de mercadorias, tradicionalmente ocupações de caráter feminino, que permitiram a expansão da ocupação das mulheres no mercado de trabal ho goiano. A pesar do crescimento do emprego feminino nas atividades industriais e na administração pública, ambos incorporam um percentual relativamente baixo de trabalhadoras em comparação ao setor terciário.

Se estabelecermos uma comparação com a média nacional, podemos observar, pela Tabela 14 , que esse quadro não difere muito do nacional; são poucas as diferenças, mas uma chama a atenção: os indicadores de formalidade e precariedade da ocupação feminina são piores para o estado de Goiás em relação ao país. A distribuição da ocupação feminina no estado concentra uma parcela maior de mulheres adultas em

Tabela 12 - Distribuição das pessoas adultas ocupadas por gênero e posição na ocupação Goiás, anos: 1993 e $2003(\%)$

\begin{tabular}{|c|c|c|c|c|c|c|}
\hline \multirow[t]{2}{*}{$\begin{array}{l}\text { Posição na ocupação e } \\
\text { Categoria do emprego }\end{array}$} & \multicolumn{3}{|c|}{$\begin{array}{c}\text { Distribuição das pessoas } \\
\text { adultas ocupadas por gênero } \\
1993\end{array}$} & \multicolumn{3}{|c|}{$\begin{array}{c}\text { Distribuição das pessoas } \\
\text { adultas ocupadas por gênero } \\
2003\end{array}$} \\
\hline & Total & Homens & Mulheres & Total & Homens & Mulheres \\
\hline Empregados & 52,01 & 60,48 & 37,46 & 58,08 & 64,35 & 48,56 \\
\hline Com carteira de trabalho assinada & 19,78 & 21,83 & 16,26 & 26,64 & 29,24 & 22,70 \\
\hline Militares e funcionários públicos estatais & 6,68 & 5,00 & 9,58 & 8,27 & 6,14 & 11,50 \\
\hline $\begin{array}{l}\text { Outros s/ carteira de trabalho assinada } \\
\text { e sem declaração }\end{array}$ & 25,55 & 33,64 & 11,62 & 23,17 & 28,97 & 14,35 \\
\hline Trabalhadores domésticos & 9,02 & 0,41 & 23,83 & 9,59 & 0,98 & 22,67 \\
\hline Com carteira de trabalho assinada & 0,46 & 0,05 & 1,16 & 1,93 & 0,47 & 4,14 \\
\hline Sem carteira de trabalho assinada & 8,56 & 0,36 & 22,67 & 7,66 & $\mathbf{0 , 5 1}$ & 18,53 \\
\hline Conta própria & 19,42 & 23,65 & 12,16 & 20,97 & 24,69 & 15,30 \\
\hline Empregadores & 5,21 & 7,23 & 1,74 & 4,85 & 6,36 & 2,54 \\
\hline Não-remune rados & 7,21 & 7,43 & 6,82 & 3,58 & 2,48 & 5,26 \\
\hline $\begin{array}{l}\text { Trabalhadores na produção para o próprio } \\
\text { consumo }\end{array}$ & 6,95 & 0,54 & 17,95 & 2,84 & 0,98 & 5,67 \\
\hline $\begin{array}{l}\text { Trabalhadores na construção para o } \\
\text { próprio uso }\end{array}$ & 0,18 & 0,26 & 0,04 & 0,09 & 0,16 & $\mathbf{0 , 0 0}$ \\
\hline Total & 100,00 & 100,00 & 100,00 & 100,00 & 100,00 & 100,00 \\
\hline $\begin{array}{l}\text { Ocupados em atividades informais e/ou } \\
\text { precárias }\end{array}$ & 67,87 & 65,88 & 71,26 & 58,31 & 57,79 & 59,11 \\
\hline
\end{tabular}

Fonte: IBGE; Pnad: 1993 e 2003. Elaboração da própria autora. 
atividades precárias e sem víncul os formais do que o verificado no quadro nacional.

Enquanto em 1999, 61,5\% das ocupações femininas no país estiveram atreladas às condições de informalidade, o percentual no estado foi de $64,5 \%$. Já em 2003 , esse percentual passou para $58 \%$ no país e continuou maior no estado, em torno de $59 \%$.

Essa comparação é oportuna por que houve, ao longo dos anos de 1990, uma piora dosindicadores deassal ariamento e formalização da mão-de-obra feminina no país, com pequena melhora em 2003. M esmo com a deterioração das relações e condições de trabalho feminino verificada no quadro nacional, Goiás, que apresentou taxas de crescimento do PIB superiores às nacionais no período, ainda permanece com uma menor capacidade de geração de empregos de melhor qualidade para sua população feminina em relação à nacional.

Se levarmos em conta a evolução do perfil dos rendimentos médios das mulheres ocupadas em suas atividades principais ao longo do período, vamos encontrar um outro indicador da quali- dade dos trabalhos gerados para a população feminina. Os dados da Tabela 14 permitem verificar que mais de $55 \%$ das mul heres adultas ocupadas em 1993 ganhavam até um salário mínimo por mês, perfazendo um total percentual de quase $80 \%$ de mulheres ganhando no máximo dois salários mínimos. Em 2003, 76\% das trabal hadoras goianas recebiam até dois salários mínimos por mês, enquanto $46 \%$, até um salário mínimo.

Houve, sem dúvida nenhuma, uma melhora no perfil dos rendimentos das mulheres ocupadas entre 1993 e 2003, porém estes continuam em níveis bastante inferiores. Esses patamares são efetivamente muito baixos, inclusive se comparados com o perfil de rendimentos masculinos. Em 1993,60\% dos homens ocupados ganhavam até no máximo dois salários mínimos, com 31\% recebendo até um salário mínimo. Em 2003, esses valores se reduziram para $58 \%$ e $22 \%$, respectivamente. Ou seja, além de contarem com uma participação mais precária, menos segura e estável no mercado de trabalho, as mulheres também têm um perfil de remuneração inferior ao patamar masculino.

Tabela 13 - Distribuição das mulheres adultas ocupadas por posição na ocupação. G oiás e B rasil: anos 1999 e2003 (\%)

\begin{tabular}{|c|c|c|c|c|}
\hline \multirow[t]{2}{*}{$\begin{array}{l}\text { Posição na ocupação e } \\
\text { Categoria do emprego }\end{array}$} & \multicolumn{2}{|c|}{$\begin{array}{c}\text { Distribuição das } \\
\text { mulheres adultas } \\
\text { ocupadas por gênero } \\
1999\end{array}$} & \multicolumn{2}{|c|}{$\begin{array}{c}\text { Distribuiçãodas } \\
\text { mulheres adultas } \\
\text { ocupadas por gênero } \\
2003\end{array}$} \\
\hline & Brasil & Goiás & Brasil & Goiás \\
\hline Empregadas & 43,95 & 43,12 & 47,54 & 48,56 \\
\hline $\mathrm{C} /$ carteira de trabalho assinada & 23,24 & 18,23 & 25,64 & 22,70 \\
\hline Militares e func. públicas estat. & 8,94 & 11,96 & 8,86 & 11,96 \\
\hline Outras s/ carteira assinada & 11,76 & 12,93 & 13,04 & 14,35 \\
\hline Trabalhadoras domésticas & 17,19 & 24,43 & 17,31 & 22,67 \\
\hline $\mathrm{C} /$ carteira de trabalho assinada & 4,08 & 2,69 & 4,52 & 4,14 \\
\hline S/ carteira assinada & 13,10 & 21,74 & 12,70 & 18,53 \\
\hline Conta própria & 16,12 & 15,62 & 16,29 & 15,30 \\
\hline Empregadoras & 2,19 & 2,61 & 2,51 & 2,54 \\
\hline Não-remune radas & 12,27 & 6,12 & 9,33 & 5,26 \\
\hline Trabalhadoras na prod. e const. p/ o próprio consumo e uso & 8,30 & 8,10 & 7,01 & 5,67 \\
\hline TOTAL & 100,00 & 100,00 & 100,00 & 100,00 \\
\hline Ocupadas em atividades informais e/ou precárias & 61,55 & 64,51 & $\mathbf{5 8 , 3 7}$ & 59,11 \\
\hline
\end{tabular}

Fonte: IBGE; Pnad: 1999 e 2003; elaboração da própria autora. 
Tabela 14 - Distribuição das pessoas adul tas ocupadas por nível de rendimento mensal na ocupação principal e por gênero. Goiás, anos: 1993 e 2003 (\%)

\begin{tabular}{|l|r|r|r|r|}
\hline \multirow{2}{*}{ Classes de rendimento mensal } & \multicolumn{2}{|c|}{$\begin{array}{r}\text { Distribuição dos ocupados adultos } \\
\mathbf{1 9 9 3}\end{array}$} & $\begin{array}{r}\text { Distribuição dos ocupados adultos } \\
\mathbf{2 0 0 3}\end{array}$ \\
\hline \multirow{2}{*}{ Até 1 SM } & Homens & Mulheres & Homens & Mulheres \\
\cline { 2 - 5 } Mais de 1 a 2 SM & $\mathbf{3 1 , 2}$ & $\mathbf{5 5 , 3}$ & $\mathbf{2 2 , 3}$ & $\mathbf{4 6 , 0}$ \\
Mais de 2 a 3 SM & $\mathbf{2 9 , 0}$ & $\mathbf{2 3 , 7}$ & $\mathbf{3 5 , 7}$ & $\mathbf{3 0 , 2}$ \\
Mais de 3 a 5 SM & 12,4 & 6,5 & 18,6 & 10,5 \\
Mais de 5 a 10 SM & 12,0 & 7,2 & 12,2 & 7,4 \\
Mais de 10 SM ou mais & 7,8 & 4,1 & 6,8 & 4,1 \\
Total (\%) & 6,3 & 2,4 & 4,4 & 1,7 \\
\hline
\end{tabular}

Fonte: IBGE, Pnad: 1993 e 2003. Elaboração da própria autora.

A análise do perfil dos rendimentos médios femininos por posição na ocupação apresenta um quadro ainda menos promissor.

A pesar do número de empregos femininos crescer no período, inclusive em rel ação àqueles com vínculos formais, a baixa remuneração da mão-de-obra feminina permaneceu ao longo do período - em 1993, 79,7\% das mul heres adultas empregadas ganhavam até no máximo três salários mínimos, enquanto, em 2003, esse percentual subiu para $81,5 \%$ (Tabela 15).

Q uanto às trabal hadoras domésticas, se, em 1993, 88\% dessas mulheres ganhavam até no máximo um salário mínimo, e $99,5 \%$ até no máximo três, em 2003, 77,5\% ganhavam até um salário mínimo, só que $100 \%$ destas não ganhavam mais do que três salários mínimos. Sendo esta a atividade isolada com maior concentração de mul heres adultas ocupadas, é possível determinar o quão precárias são as ocupações femininas no estado, se considerarmos também 0 seu perfil de remuneração.

Se houve al guma melhora para as trabal hadoras domésticas, apesar de permanecerem em níveis muito baixos de remuneração, o mesmo não pode ser afirmado para as mulheres que atuam por conta própria. Em 1993, 46\% dessas trabal hadoras recebiam até no máximo um salário mínimo. Esse percentual subiu para $49,5 \%$ em 2003. Temos aqui um mito importante a averiguar. 0 senso comum tem afirmado que muitos trabalhadores, homens e mulheres, aderiram às atividades por conta própria para
Tabela 15 - Distribuição das mulheres adultas ocupadas por posição na ocupação e rendimento médio mensal. Goiás, anos: 1993 e 2003

\begin{tabular}{|c|r|r|}
\hline $\begin{array}{c}\text { Posição na ocupação e } \\
\text { classes de rendimento } \\
\text { médio mensal }\end{array}$ & $\begin{array}{c}|c| \\
\text { Distribuição (\%) das } \\
\text { mulheres adultas } \\
\text { ocupadas }\end{array}$ \\
\hline Empregadas & $\mathbf{1 9 9 3}$ & $\mathbf{2 0 0 3}$ \\
\cline { 2 - 3 } Até 1 SM & $\mathbf{1 0 0 , 0}$ & $\mathbf{1 0 0 , 0}$ \\
Mais de 1 a 3 SM & 40,1 & 32,1 \\
Mais de 3 a 5 SM & 39,6 & 49,4 \\
Mais de 5 SM ou mais & 10,7 & 9,4 \\
Trabalhadoras domésticas & $\mathbf{1 0 0 , 0}$ & $\mathbf{1 0 0 , 0}$ \\
Até 1 SM & 87,8 & 77,5 \\
Mais de 1 a 3 SM & 11,6 & 22,5 \\
Mais de 3 a 5 SM & 0,2 & 0,0 \\
Mais de 5 SM ou mais & 0,0 & 0,0 \\
Conta própria & $\mathbf{1 0 0 , 0}$ & $\mathbf{1 0 0 , 0}$ \\
Até 1 SM & 46,1 & 49,4 \\
Mais de 1 a 3 SM & 36,6 & 34,0 \\
Mais de 3 a 5 SM & 8,8 & 10,1 \\
Mais de 5 SM ou mais & 5,8 & 6,5 \\
Empregadoras & $\mathbf{1 0 0 , 0}$ & $\mathbf{1 0 0 , 0}$ \\
Até 1 SM & 10,3 & 8,1 \\
Mais de 1 a 3 SM & 20,0 & 35,1 \\
Mais de 3 a 5 SM & 15,4 & 21,6 \\
Mais de 5 SM ou mais & 53,9 & 35,2 \\
\hline Font & \\
\hline
\end{tabular}

Fonte: IBGE, Pnad: 1993 e 2003. Elaboração da própria autora. 
usufruir de um rendimento maior, livres dos limites legais que o emprego, com ou sem carteira, impõe aos seus rendimentos. 0 fato é que os rendimentos de mais da metade dessa categoria declinaram nosúltimos anos, e uma parcela relativamente menor é que pôde, na verdade, usufruir de maior renda.

Se incorporarmos ao nosso estudo a variável rendimento médio como um indicador de precariedade ocupacional, a conclusão da análise feita parece corroborar a visão de que a qualidade das ocupações femininas geradas pela atividade econômica nos últimos dez anos permanece efetivamente baixa, contribuindo para a constituição de um mercado de trabalho inadequado às aspirações de melhor inserção feminina na sociedade moderna.

\section{Conclusão}

A análise dos dados da Pnad/IBGE sobre trabal ho e rendimento em $G$ oiás permite verificar que as mulheres ampliaram seu espaço no mercado de trabalho urbano nos últimos anos (1993-2003).

Contudo, se, de um lado, houve maior envolvimento das mulheres na atividade econômica, por outro lado, a geração de postos de trabal ho foi insuficiente, tendo em vista 0 aumento da taxa de desemprego feminina no estado. A qualidade dos empregos gerados, por sua vez, pouco mel horou, dado o predomínio da criação das novas ocupações no ramo de prestação de serviços, comércio de mercadorias e atividades sociais, atividades que tradicionalmente apresentam baixo grau de formalização e elevado grau de precarização das condições e relações de trabalho.

0 aprofundamento do processo de informalidade no mercado de trabal ho pode ser constatado por meio tanto da evolução das formas de inserção dos ocupados urbanos quanto do nível médio de renda.

No primeiro caso, destaca-se que o gênero feminino encontra-se sobre-representado nas categorias de trabalho doméstico, por conta própria e empregado sem carteira assinada. A inda que pese 0 aumento do emprego formal (com carteira assinada) no estado, tal crescimento foi incapaz de reverter a mai or proporção de mulheres envolvidas em ocupações informais e precárias - em 2003, quase $60 \%$ das trabaIhadoras goianas exerciam alguma ocupação informal ou precária. Se estabelecermos uma comparação por gênero, esses indicadores são menos dramáticos para a população masculina, embora também significativos.

No segundo caso, a evolução do nível médio de renda piorou para as mulheres ocupadas nas categorias de empregado e por conta própria, e melhorou para as trabalhadoras domésticas, ainda que a maioria ( $77,5 \%)$ destas últimas não receba mais do que um salário mínimo por mês. Se ef etuarmos um corte por gênero, novamente a situação feminina é mais precária do que a masculina - em 2003, 46\% das mulheres ocupadas recebiam até um salário mínimo por mês, enquanto esse percentual foi de $22,3 \%$ para os homens.

Portanto, a feminização do mercado de trabal ho em G oiás ainda é marcada por um grau elevado de precariedade e informalidade nas relações e condições de trabalho, o que não tem contribuído para melhorar as condições de vida da população feminina e, muito menos, para atenuar os indicadores de discriminação, pobreza e exclusão social que recaem sobre ela.

A bstract: The present research, based in data from the National Research per Sample of Domiciles (Pnad, IBGE), tries to analyze the conditions of employment and income in the growth of women's participation in the work market at Goias State. The aim is to identify, quantify and understand the included grades of degradation and informality in conditions, relations and income of the female work at the contemporary Goiás State's work market. The informality is treated here as a quality degradation tendency of work in effective occupations, including inefficient forms of insertion for the women labor force in the work market. The employed criteria were supported by women's labor participation in the PEA (Economically Active Population), unemployment and income indices, structure of Economically Active Population, modifications in the grade of formalization in Second Gender occupations and finally, economic activity indices in Goias State from 1993 to 2003.

K ey words: labor; gender; informal labor. 


\section{Referências}

BALTA R, P.E.A. Estrutura econômica e emprego urbano na década de 1990. In: PRONI, M. W.; HENRIQUE, W. (Orgs.). Trabalho, mercado e sociedade: 0 Brasil nos anos 90. São Paulo: Editora Unesp, 2003. cap. 3, p. 107-152.

BOSCO, C. A. Trabalho informal: Realidade ou relação de emprego fraudulenta? Curitiba: Juruá Editora, 2003.

BRUSCHINI, C.; SORJ, B. Excluídas do Progresso. Boletim Viver Diferentemente - B eijing95. Rio de J aneiro: Instituto Brasileiro de A nálises Sociais e Econômicas (I base), 1995.

CACCIAM ALI, M. C. A composição do mercado informal de trabal ho e o papel do mercado de trabal ho na redução da pobreza. In: FIPE/M TE. Estudos e análises com vistas à definição de políticas, programas e projetos relativos ao mercado de trabalho brasileiro. São Paulo: Fipe, 2002. [Tema 52].

DALBOSCO, E. 0 trabalho informal no Brasil: A nálise, conceito, pesquisas e impactos sociais. B rasília, 2000. Dissertação (M estrado em Política Social ) - Departamento de Serviço Social, U niversidade de B rasília.

DIEESE. Escritório Regional de Goiás. Perfil do mercado de trabalho na década de 90 em Goiás. Goiânia: Dieese-GO, 2003. [Elaboração de Leila B rito].

ESTEVAM , L. 0 tempo da transformação: estrutura edinâmica da formação econômica de G oiás. G oiânia: Editora do A utor, 1998.

HIRATA, H. Por quem os sinos dobram? Globalização e divisão sexual do trabal ho. In: EM ÍLIO, M . et.al. (Orgs.). Trabalho e cidadania ativa para as mulheres: Desafios para as políticas públicas. São Paulo: Coordenadoria Especial para as Mulheres, Governo do Estado de São Paulo, 2003. p. 15-30. [Caderno n. 3].

M AIA , V. E. D esenvolvimento econômico de Goiás. Goiânia: Kelps, 2005.

MATTOSO, J. 0 Brasil desempregado. 2. ed. São Paulo: Fundação Perseu A bramo, 1999.

LEONE, E. T. O trabalho da mulher em regiões metropolitanas brasileiras. In: PRONI, M. W.; HENRIQUE, W. (Org.). Trabalho, mercado e sociedade: 0 Brasil nos anos 90. São Paulo: Editora Unesp, 2003. cap. 5, p. 199-230.
POCHM A N N, M . 0 trabalho sob fogo cruzado. São Paulo: Contexto, 1999.

R aízes da grave crise do emprego no B rasil. In:FONTES, R.; A RBEX, M .A. (Ed.). D esemprego e mercado de trabal ho: Ensai os teóricos e empíricos. Viçosa: UFV, 2000. Cap. 5, p. 185-214.

ROY, L. 0 modo de ser mulher trabalhadora na reestruturação produtiva. Campinas, SP: Alínea, 1999.

SCORZA FAVE, L. G. D. S. Caracterização da inserção feminina no mercado de trabalho e seus efeitos sobre a distribuição de renda. São Paulo, 2004. Tese (D outorado em Economia) - Faculdade de Economia, A dministração e Contabilidade, Departamento de Economia, Universidade de São Paulo.

SILVA, E. R. A economia goiana no contexto nacional. Campinas, 2002. Dissertação (M estrado em E conomia) - Instituto de E conomia, Universidade Estadual de Campinas.

SINGER, P. Trabal ho informal: origens e evolução. In: JAKOBSEN, K. et al. Mapa do trabalho informal. São Paul o: Fundação Perseu A bramo, 2000. cap. 1, p. 11-13.

TOKM AN, V. E. Dela informalidad a la modernidad. In: TOK M A N, V. E. (Org.). D e la informalidad a la modernidad. Santiago: OIT, 2001. cap. 1, p. 19-38.

VALENZUELA, M. E. Desigualdad de género y pobreza en A mérica Latina. In: PACHECO, F. Incorporación de género en las políticas de erradicación de la pobreza y generación de empleo em América Latina. San José: OIT, 2003. cap. 3, p. 289-338.

Fontededados consultada:

IBGE. Pesquisa Nacional por Amostra de Domicílios (Pnad), 1993 a 2003. Disponível em: http:// ww2.ibge.gov.br A cesso em: abril, maio e agosto de 2005.

Censo Demográfico - 2000: Trabalho e rendimento, 2000. Disponível em: http:// ibge.gov.br/ home/estatística/população/censo2000/default trabalho rendimento.shtm. A cesso em: agosto de 2005.

SEPLAN-GO. SEPIN - Gerência de Estatística Socioeconômica - 2005. Goiás em dados - 2005. Disponível em: http://portalsepin.seplan.go.gov.br/ A cesso em: setembro de 2005. 
